\title{
Dos Fios que Desafiam Significados no Mundo: Notas Antropológicas Sobre Poéticas e Políticas de Morte e de Vida
}

\section{About Threads that Defy Meanings in the World: Anthropological Notes on Poetics and Policies on Death and Life}

\section{Giovana Acacia Tempesta}

Universidade de Brasília, Brasília, Distrito Federal, Brasil

\section{RESUMO}

A obra da artista visual Rosana Paulino tematiza de modo original as conexões entre cultura visual e preconceito de raça e gênero no Brasil contemporâneo. Partindo dos conceitos de biopolítica e necropolítica, formulados por filósofos e historiadores de outros continentes, encontramos o conceito de bio-necropolítica à brasileira (LIMA, 2018), que nos ajuda a refletir sobre os impactos de longa duração de práticas, ideias e estereótipos forjados durante o período escravocrata. Todavia, a antropologia nos permite compreender que a perdurabilidade de dispositivos racistas e misóginos é incapaz de encobrir completamente projetos de resistência, luta e transformação da realidade, tomados como expressões de estilos singulares de criatividade-invenção (WAGNER, 2012). Ao colocarmos em relação algumas obras de Rosana Paulino e certas ideias formuladas pela intelectual e ativista negra Lélia Gonzalez, percebemos que o alcance do trabalho da artista extrapola o mundo das artes e interessa também a uma antropologia que se indaga sobre os meandros das relações de poder.

Palavras-chave: Cultura e poder, Artes visuais, Rosana Paulino, Lélia Gonzalez, Criatividade. 


\section{ABSTRACT}

The work of visual artist Rosana Paulino deals in an original way with the connections between visual culture and prejudice of race and gender in contemporary Brazil. Starting from the concepts of biopolitics and necropolitics, formulated by philosophers and historians from other continents, we find the concept of Brazilian bio-necropolitics (LIMA, 2018), which helps us to reflect on the long-lasting impacts of practices, ideas and stereotypes forged during the slavery period. However, anthropology allows us to understand that the durability of racist and misogynistic devices is not able to completely cover up projects of resistance, struggle and transformation of reality, which express singular styles of creativity-invention (WAGNER, 2012). When we put in relation some works of Rosana Paulino and certain ideas formulated by the black intellectual and activist Lélia Gonzalez, we realize that the scope of the artist's work goes beyond the world of the arts and also interests an anthropology that inquiries about the intricacies of power relations.

Keywords: Culture and power, Visual arts, Rosana Paulino, Lélia Gonzalez, Creativity.

\section{COLOCANDO A LINHA NA AGULHA}

No presente ensaio ${ }^{1}$ focalizarei algumas obras e depoimentos da artista visual Rosana Paulino a partir da "semiótica particular" de Wagner $(2012)^{2}$, autor cujo pensamento se ancora no pressuposto de que a linguagem e o significado criam realidade. Para Wagner (2012), a invenção - na acepção de criatividade - consistiria na forma própria da nossa experiência e do nosso entendimento, e a principal tarefa da antropologia e das ciências sociais seria construir uma consciência da invenção que contemple a consciência da diferença e da contradição. Seguindo a proposta desse autor, tomo o trabalho artístico de Rosana Paulino ${ }^{3}$ como uma modalidade de invenção ou estilo de criatividade que desafia políticas de morte e inspira o engendramento de formas de vida-em-comum mais justas e plurais.

\footnotetext{
1 Este ensaio resulta de reflexões iniciadas no âmbito do curso de Antropologia Política que ministrei no $2^{\circ}$ semestre de 2019, na Universidade de Brasília. Quero agradecer pela colaboração de algumas estudantes: Anyelle Amarante e Sofia Rizzo me estimularam a dar uma forma mais substantiva a ideias apresentadas durante o semestre e também leram e comentaram as primeiras versões deste texto; e Laísa Fernanda da Silva me colocou em contato com Jordhanna Cavalcante e Marcela Costa, as quais gentilmente compartilharam comigo seus trabalhos ainda inéditos.
}

\section{Cf. GOLDMAN, 2011.}

3 No site mantido pela artista é possível encontrar fotos e comentários sobre várias de suas obras: www.rosanapaulino.com.br. 
Interessa-me apreciar as obras de Rosana Paulino a partir de certos conceitos e insights formulados por Lélia Gonzalez, antropóloga e militante do movimento negro que, nos anos 1970 e 1980, produziu uma potente reflexão crítica a respeito da conexão entre poder, racismo e sexismo, uma reflexão que vem sendo "redescoberta" somente nos últimos anos, quando as humanidades se interessaram pelo paradigma interseccional - que a autora já anunciara, sem, contudo, empregar o termo.

Se, no século XXI, a antropologia da política ${ }^{4}$ continua se mostrando relevante para ampliar e complexificar os debates sobre formas políticas (KUSCHNIR, 2007), proponho que pode ser bastante proveitoso mirar obras de arte tão provocativas quanto as que Rosana Paulino vem criando e aproximar suas motivações às de pesquisadores contemporâneos que abordam diferentes dimensões das relações raciais no Brasil e na América Latina.

Desse modo, observo que Rosana Paulino trata de forma refinada a opressão histórica contra as pessoas negras, especialmente as mulheres, ao passo que exibe variados meios de resistência e resiliência, jogando com possibilidades de criação que ampliam os sentidos de liberdade, justiça e convivência num país tão desigual como o nosso. Valendo-se de uma miríade de técnicas para lidar de forma original com o belo e o feio, ela mescla elementos de morte e vida, escancara contradições profundas e nos convoca a romper com silêncios coniventes. Por sua vez, Lélia Gonzalez $(1984,2019)$ debruçou-se sobre o lugar social, afetivo e psíquico ocupado pela mãe preta - pivô da neurose cultural brasileira - e propôs que a língua ensinada por ela, o "pretuguês", poderia unir não apenas um país, mas todo o continente em torno de um projeto de justiça social e libertação. De modo importante, essas duas mulheres investiram no manejo habilidoso do simbólico como fonte e meio de transformação de subjetividades e de formações políticas.

Recuperar brevemente o debate teórico e ético em torno dos conceitos de biopolítica, necropolítica e bio-necropolítica nos ajudará a apurar a sensibilidade para apreender a força e a potencialidade criadora dos referentes de vida entremeados às relações de dominação racializadas, presentes tanto na obra de Rosana Paulino quanto nos escritos de Lélia Gonzalez.

4 A opção pela expressão antropologia "da" política (e não "antropologia política") faz coro à crítica construtiva formulada por Peirano (1997) e outros antropólogos na década de 1990. 


\section{BIOPOLÍTICA, NECROPOLÍTICA E BIO-NECROPOLÍTICA À BRASILEIRA}

De acordo com Foucault (2018), os conceitos de biopoder e biopolítica se referem à entrada da vida na história, isto é, à entrada dos fenômenos próprios à vida da espécie humana na ordem do saber e do poder, constituindo-se então novos dispositivos de controle e sujeição. Segundo a lógica moderna do biopoder, sintetizada na máxima "fazer viver e deixar morrer", vigoraria uma divisão, inscrita no plano do orgânico, entre pessoas que devem viver e pessoas que podem morrer (FOUCAULT, 2018).

O pensador camaronês Achille Mbembe reconhece que a noção foucaultiana de biopoder é relevante, mas aponta a sua insuficiência para explicar as formas contemporâneas de soberania, sobretudo aquelas exercidas fora do continente europeu. Por isso, ele formulou a noção de "necropolítica" para apreender configurações políticas organizadas em torno da "[...] percepção da existência do outro como um atentado contra a minha vida, como uma ameaça mortal ou perigo absoluto, cuja eliminação biofísica reforçaria o potencial para minha vida e segurança [...]" (MBEMBE, 2016, p. 129-130). O autor identifica ligações inextricáveis entre o Estado moderno e o terror e sustenta que o advento da modernidade coincide com o princípio da definição de raça e sua transformação em matriz privilegiada de dominação. Na modernidade, exercitar a soberania passa a ser sinônimo de exercer controle sobre a mortalidade e definir a vida como uma manifestação de poder. A soberania definida como o direito de matar se articula, assim, à ideia de política como trabalho da morte.

Tomando como referência o continente africano, Mbembe (2016) focaliza o racismo enquanto experiência demolidora da alteridade e afirma que "[...] a raça foi a sombra sempre presente sobre o pensamento e a prática das políticas do Ocidente, especialmente quando se trata de imaginar a desumanidade de povos estrangeiros ou dominá-los" (p. 128). Ele lembra que, para Foucault, racismo é uma tecnologia destinada a permitir o exercício do biopoder, cuja função primordial seria regular a distribuição de morte e tornar possíveis as funções assassinas do Estado.

O terror moderno surge a partir da escravidão, definida como uma experimentação biopolítica, no âmbito do sistema colonial, e a sua principal consequência seria a criação do estado de exceção por meio de uma figura emblemática e paradoxal. O paradoxo se origina no próprio contexto de colonização, em que a figura do escravo enquanto ser humano é obliterada por uma 
"sombra personificada", que indica uma perda tripla: a perda de um "lar", a perda de direitos sobre seu próprio corpo e a perda de status político. Tais perdas se configuram então como uma forma de "expulsão da humanidade de modo geral" (MBEMBE, 2016, p. 131). No horizonte do imperialismo, a soberania se traduziu na capacidade de definir quem importava e quem não importava, quem seria descartável e quem não seria.

Entretanto, mesmo em meio a tais condições de existência, tendo a humanidade negada e sendo reduzida à sua função produtiva (identificada a força, ferramenta e instrumento de trabalho), a pessoa negra escravizada criou diferentes compreensões do tempo, do trabalho e de si mesma, mostrando-se "[...] capaz de extrair de quase qualquer objeto, instrumento, linguagem ou gesto uma representação, e ainda lapidá-la” (MBEMBE, 2016, p. 132).

As ideias elaboradas por Foucault e Mbembe têm sido apropriadas por pesquisadores e ativistas negros que vêm estudando e denunciando o problema persistente da mortandade desmedida da população negra e pobre no Brasil.

Interessada em "pensar a emergência e pulverização microcapilares das relações e mecanismos de poder, principalmente em contextos sociais advindos dos processos de colonização e onde os elementos de colonialidade ainda são fortes" (LIMA, 2018, p. 22), a pesquisadora Fátima Lima elaborou a ideia de uma bio-necropolítica à brasileira para abordar a problemática do genocídio da população negra no país ${ }^{5}$. A autora propõe a adoção de lentes conceituais e metodológicas que permitam compreender a construção da sociedade brasileira a partir do eixo analítico da escravatura, desvendando-se a complexidade do "conjunto semiótico" formado pelo mito da democracia racial, pelo imperativo da miscigenação e pelo projeto de embranquecimento da população, que ainda hoje se pode reconhecer em práticas cotidianas (LIMA, 2018, p. 29).

Por sua vez, em seu estudo sobre as estratégias territoriais de dominação e contenção social que operam na cidade de São Paulo, Alves (2011) identificou conexões entre as práticas necropolíticas estatais do início do século XXI e o processo de reforma urbanística levado a cabo ao final do século XIX, as quais produziram verdadeiros enclaves raciais. Conceitualizando raça como "[...] uma realidade socialmente construída que estrutura as relações sociais e define não apenas o acesso diferenciado à cidadania, mas também o direito à vida" (ALVES,

5 A expressão "genocídio" é empregada nos estudos sobre discriminação racial para se referir a um conjunto de práticas veladas ou explícitas que provocam efeitos negativos, de forma sistemática, na qualidade de vida da população negra, tais como mortes violentas, encarceramento em massa, taxas de desemprego e subemprego, ausência ou dificuldade de acesso a serviços de saúde, educação, infraestrutura, lazer e transporte; a expressão articula-se à ideia de "ato de violência estatal", que se refere a todo ato tolerado ou incentivado pelo Estado com a finalidade de criar, justificar, explicar ou reproduzir hierarquias de diferença e relações de desigualdade (ALVES, 2011, p. 126). 
2011, p. 109), o autor defende que o projeto estatal de higienização em São Paulo se erigiu em torno da imagem estereotipada da favela como locus de perigo, desordem, degradação, sujeira e doenças - uma imagem que mediou a conversão dos moradores de favela em "não cidadãos". Alves (2011) afirma que o perfil das pessoas mortas pelas polícias civil e militar é composto predominantemente por homens jovens, negros e moradores das áreas mais pobres do município, o que indicaria a vigência de uma "metodologia da morte", segundo a qual o local de moradia, a idade, a raça e o gênero seriam condicionantes da violência policial. Para o pesquisador, essa "distribuição calculada da morte e da punição" converge para uma economia da violência peculiar, que faz da favela o espaço paradigmático de seu exercício (ALVES, 2011, p. 117).

Essas duas miradas analíticas indicam a que ponto o trabalho da morte é racialmente localizado na sociedade brasileira, mas interessa considerar os deslocamentos significativos que têm sido efetuados por meio da expressão artística. Vamos a eles.

\section{REINVENTANDO MUNDOS: FORMAS ARTÍSTICAS E RELAÇÕES DE PODER}

Refletindo a respeito das consequências de longo prazo do processo de modernização do Brasil, o antropólogo Osmundo Pinho (2007) sublinha a importância da apropriação criativa de elementos da indústria cultural e da cultura negra global (como o reggae e o funk-soul) por parte de jovens afrodescendentes brasileiros, que teve lugar na segunda metade do século XX. Para o autor interessa:

[...] perceber o caráter de mediação intelectual necessária para a formação de uma consciência rebelde e transformadora das representações dominantes sobre o negro, assim como de seu lugar na estrutura social. Sendo assim, a emancipação política e material está compreendida por essa emancipação intelectual que passa pela desalienação negra e sua libertação ideológica e subjetiva das representações racistas. A ação afrodescendente transformadora, "atividade consciente", articula-se e na verdade pressupõe uma consciência emancipada ou em busca de emancipação. (PINHO, 2007, p. 90).

Pinho (2007) entende que o projeto de modernização da sociedade brasileira, construído a partir do declínio do sistema escravocrata e visando a configuração de um sistema de classes, supunha o fim do "problema negro" e, por extensão, o fim dos próprios negros como sujeitos 
sociais diferencialmente posicionados (p. 91). Por esse motivo, as pessoas e coletividades negras foram excluídas em termos políticos, sociais e simbólicos daquele projeto. Mas o equacionamento desse "problema" continua em aberto nas primeiras décadas do século XXI, pois a afirmação desses novos sujeitos sociais, “[...] representando a diferença como modo de articulação do político com a vida cotidiana, e da história com a conquista de novos direitos [...]," ainda não é percebida "[...] como um desenvolvimento positivo rumo a uma maior e mais profunda democratização" (p. 91-92). ${ }^{6}$ Mesmo assim, o mundo das artes desponta há algum tempo como locus profícuo de visibilização das questões que afetam as coletividades negras marginalizadas e a sua potência criativa e emancipadora.

Na década de 1950, na cidade de São Paulo, onde Rosana Paulino nasceu e ainda mora, a catadora Carolina Maria de Jesus registrara em seu diário sentimentos e ideias pungentes a respeito da vida na favela do Canindé (JESUS, 2014). Mais tarde, no contexto da redemocratização do país, a banda paulistana Racionais MC's difundiu letras ácidas, que contêm uma crítica social impactante e apontam os limites racializados do nosso regime de governo (CAVALCANTE, 2019).

Nos últimos anos, as obras de escritoras negras, jovens e seniores vêm ganhando espaço nos círculos artísticos e intelectuais, dentre as quais se destaca o nome de Conceição Evaristo, que recebeu o prestigioso Prêmio Jabuti em 2019. Para ela, que se refere à escrita como espaço de "escrevivência, a literatura funciona como uma espécie de vingança, como uma ferramenta na luta contra o racismo e o machismo que constituem as bases da sociedade e da literatura brasileira ${ }^{7}$.

No nicho das artes visuais vem recebendo destaque o nome de Rosana Paulino, artista que traz para o primeiro plano a memória de um passado nacional infame. Suas obras podem ser interpretadas como uma forma de resistência criativa à bio-necropolítica à brasileira e como testemunho vívido da violência que ainda hoje perpassa pessoas e relações no Brasil. A experiência estética propiciada pela artista parece falar a respeito de "uma luta sobre condições materiais e significado" (BRAH, 2006, p. 360) e, nesse sentido, desdobra-se em uma experiência de cunho ético e reflexivo. Apreciemos agora alguns de seus marcantes inv(t)entos.

6 Vale lembrar que, convergindo com a proposição geral de Pinho (2007), a pensadora feminista negra Patricia Hill Collins (2019) elaborou uma excelente análise das expressões culturais de mulheres afro-americanas, especialmente o blues e a literatura, enquanto práticas de autodefinição que rejeitam imagens controladoras (objetificadoras) e impulsionam a mudança social.

7 Sobre as ideias de Conceição Evaristo, ver, por exemplo, o material disponível no sítio eletrônico do projeto cultural Ocupação: https://www.itaucultural.org.br/ocupacao/conceicao-evaristo/escrevivencia/ Acesso em: 20 jan. 2020). 


\section{ALINHAVANDO OUTROS SENTIDOS, FALSEANDO 0 ESQUECIMENTO}

Rosana Paulino é uma mulher negra, artista plástica, pesquisadora e professora nascida na periferia da cidade de São Paulo em 1967, filha de uma empregada doméstica e de um carregador. Ela se doutorou em Artes Plásticas pela Escola de Comunicações e Artes da Universidade de São Paulo, foi bolsista da Fundação Ford e da Fundação Rockefeller e despontou no cenário das artes na década de 1990. Em termos cronológicos, Rosana Paulino não faz parte da geração de jovens negros que ingressou na universidade pública por meio do sistema de cotas raciais e que compõe um florescente conjunto de artistas e produtores culturais, mas ela percebe sua obra como conectada às demandas e inquietações dessas pessoas (CARVALHO; TVARDOVSKAS; FUREGATTI, 2018, p. 159). Ela realiza gravuras, desenhos, fotografias, esculturas e instalações sempre dialogando com textos de história e sociologia e atenta às interações entre arte, ciência e história. Suas obras já foram expostas em galerias no Brasil e em vários outros países e, nos últimos anos, têm recebido a atenção de vários veículos de comunicação e também de pesquisadores do campo da arte $^{8}$. Além disso, o trabalho de Rosana Paulino já serviu de inspiração para oficinas de artes visuais com jovens estudantes, orientadas pela perspectiva da educação multicultural crítica (NOVAIS, 2018).

A artista focaliza a construção das subjetividades marcadas pelo legado da escravidão e se indaga sobre o lugar da mulher negra na sociedade brasileira e nas artes - que, afinal, é o seu próprio lugar de fala. Ela apresenta uma crítica contundente à visão colonialista da história do Brasil, que fundamenta uma noção falsa de democracia racial (ainda vigente) e alimenta o preconceito racial. Podemos perceber sua obra como uma manifestação da consciência emancipada, insubordinada e rebelde mencionada por Pinho (2007), uma expressão de descolonização intelectual entendida como uma etapa da emancipação subjetiva e consequente transformação da sociedade como um todo.

Rosana Paulino assim se exprime sobre sua motivação para criar, que surge da vida vivida, das experiências cotidianas, e se aproxima da cultura popular e do artesanato:

[...] faz parte do meu fazer artístico apropriar-me de objetos do cotidiano ou elementos pouco valorizados para produzir meus trabalhos. Objetos

8 Ver, por exemplo, SIMIONI, 2010; MARQUES e MYCZKOWSKI, 2016; FERREIRA, 2020. 
banais, sem importância. Utilizar-me de objetos do domínio quase exclusivo das mulheres. Utilizar-me de tecidos e linhas. Linhas que modificam o sentido, costurando novos significados, transformando um objeto banal, ridículo, alterando-o, tornando-o um elemento de violência, de repressão. O fio que torce, puxa, modifica o formato do rosto, produzindo bocas que não gritam, dando nós na garganta. Olhos costurados, fechados para o mundo e, principalmente, para sua condição no mundo. ${ }^{9}$

Além disso, para ela:

Ligar as histórias de pessoas, principalmente mulheres que não são valorizadas, é um modo de sobreviver em um meio que nos tira a humanidade, é falsear o esquecimento. É trazer esta mão negra no que ela tem de mais forte, de criação, é a mão de quem assentou esta terra em diversos sentidos. [...] 'enredar' estas histórias, sejam elas belas ou sofridas, é um tributo a esta criação feminina, tantas vezes vista como 'menor' ou sem importância por nossa sociedade. (CARVALHO; TVARDOVSKAS; FUREGATTI, 2018, p. 151).

A primeira exposição individual da artista em uma prestigiosa galeria brasileira aconteceu em 2018, na Pinacoteca de São Paulo, e recebeu o expressivo título A costura da memória ${ }^{10}$. Com a intenção declarada de influenciar a sensibilidade das espectadoras e dos espectadores, ela explora possibilidades de um certo padrão de articulação de opressões, joga com as formas de categorização predominantes e, assim, nutre a esperança necessária à criação de um outro projeto de futuro.

Rosana Paulino afirma que pensa a arte como comunicação de mão dupla, na qual a resposta do público é fundamental para o delineamento dos sentidos (DIÁLOGOS AUSENTES, 2016). Quando perguntada sobre as disputas inerentes ao mundo da arte, explicou que não se interessa pelo reconhecimento pessoal em termos exclusivamente autorais, mas sim pela possibilidade de tratar de temas pouco discutidos no país e de ocupar espaços que favoreçam a ampliação do público espectador de sua obra (CARVALHO; TVARDOVSKAS; FUREGATTI, 2018, p. 157-159). Partindo de um não lugar - o das mulheres negras e periféricas no campo das artes visuais - e se indagando sobre as razões de ser desse interdito, Rosana Paulino apresenta uma contribuição importante para questionar e desmontar os estereótipos socialmente reservados para esses sujeitos sociais e logra "assentar" um lugar incontornável no mundo da arte.

As obras de arte nas quais me deterei a seguir me levaram a estabelecer conexões férteis

9 O parágrafo foi retirado de um texto de autoria da própria artista, disponível em: http://www.rosanapaulino.com. br/blog/2009/07/. Acesso em: 09 dez. 2019.

10 Apreciações refinadas dessa exposição foram elaboradas por REINA, 2018; MENEZES, 2019. 
com algumas ideias elaboradas por Lélia Gonzalez, as quais têm sido recentemente retomadas por pesquisadoras e pesquisadores empenhadas(os) em construir lentes não colonialistas para compreender e recriar a autoimagem da sociedade brasileira ${ }^{11}$. Buscarei entremear aspectos da biografia e da produção intelectual e política de Lélia Gonzalez a aspectos correspondentes relativos a Rosana Paulino, à maneira de um "modelo" analógico (no sentido wagneriano) que nos possibilite interpretar certos temas presentes na obra da artista visual.

Para tanto, é necessário apresentar brevemente Lélia Gonzalez. Filha de uma mulher de origem indígena e de um homem negro, ambos da classe trabalhadora, ela nasceu em 1935 em Belo Horizonte (MG), mas passou boa parte da vida no Rio de Janeiro, onde estudou história, geografia, filosofia, comunicação, psicanálise e antropologia. Em 1978 ela fundou o Movimento Negro Unificado Contra a Discriminação Racial (depois apenas Movimento Negro Unificado-MNU), junto com Abdias do Nascimento; nos anos 1980 fundou o Nzinga Coletivo de Mulheres Negras e se associou à Fundação Ford. Lélia viajou para várias partes do Brasil e para vários países com o intuito de conhecer intelectuais negros de renome e realidades distintas da sua própria. Ela teve uma participação relevante na política partidária e em outros espaços institucionais no contexto da democratização do país, lembrando sempre que as mulheres negras na América Latina desenvolveram a sua militância no interior do movimento negro, não no interior do movimento de mulheres. Sua morte aconteceu de forma prematura, em 1994. De acordo com Pinho (2019), Lélia Gonzalez refletiu de modo incisivo sobre a magnitude injustificada da violência estatal e da violência estrutural mais ou menos difusa que afeta até hoje as pessoas negras no Brasil, por isso a sua obra ajuda a compreender o genocídio da população negra enquanto dispositivo necropolítico de construção da nação.

Passarei agora à apreciação de cinco trabalhos de Rosana Paulino, mas não sem antes remarcar a imensidão da obra da artista, que certamente convida a novos mergulhos. Em Parede da Memória, Aracnes, Bastidores, Ama de Leite e Assentamento, Rosana Paulino demonstra de que modo a força da coletividade negra, historicamente colocada à margem da sociedade brasileira, pode agenciar uma narrativa marcadamente feminina que focaliza a morte enquanto ato de produção simultânea de arte, conhecimento, movimento e luta. Representação da memória como conexão com um fluxo de vida que atravessa gerações, exposição de um conteúdo relacional (íntimo, "doméstico") que se quer esconder sob uma capa aprazível, o trabalho reprodutivo renegado e o estatuto devassável e descartável da pessoa negra escravizada/marginalizada

11 Como se pode conferir no dossiê El pensamiento de Lélia Gonzalez, un legado y un horizonte, publicado no The Quarterly Newsletter of the Latin American Studies Association/LASA, em 2019. 
são temas que pulsam nesses trabalhos e que nos convidam a pensar sobre a configuração atual da subjetividade e da cidadania racializadas.

Imagem 1. Rosana Paulino. Imagem da instalação Parede da Memória. Tecido, microfibra, xerox, linha de algodão e aquarela. 8,0 x 8,0 x 3,0 cm cada elemento. 1994/2015.

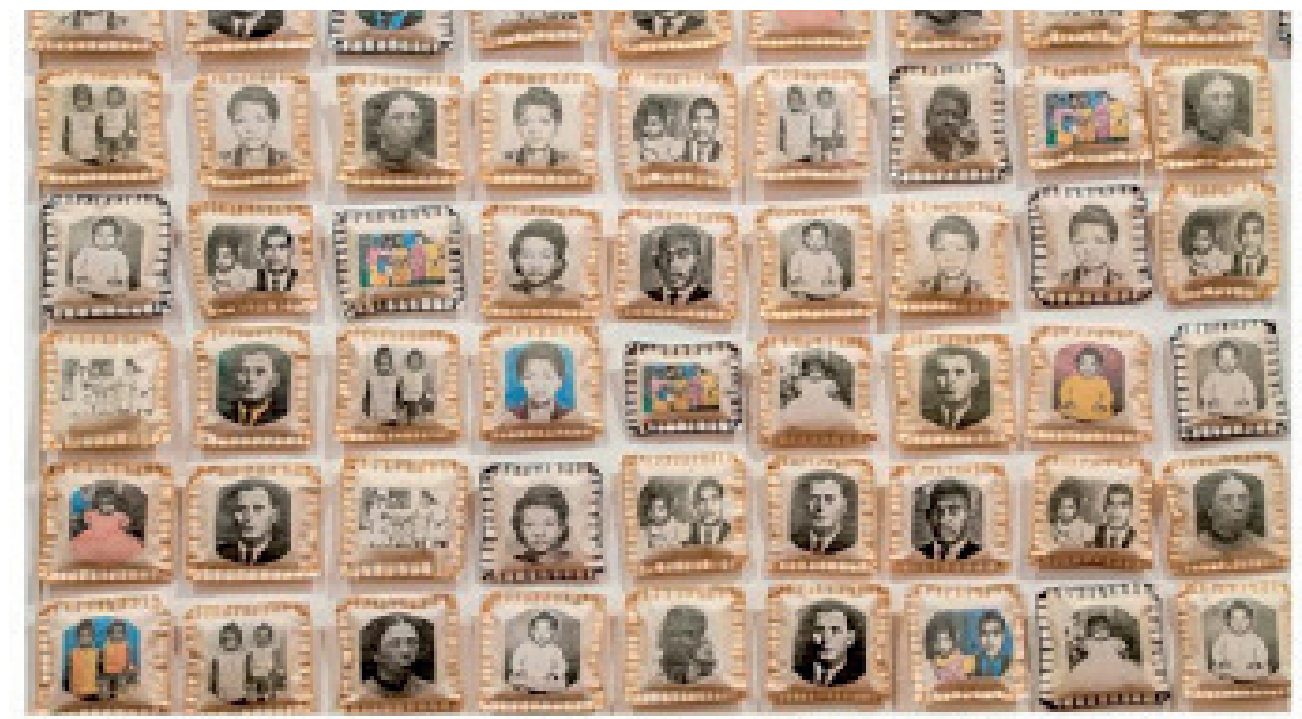

Fonte: Disponível em: http://www.rosanapaulino.com.br/. Acesso em: 14 abr. 2020.

A obra Parece da Memória foi criada entre 1994 e 2015; é um grande mosaico composto por fotografias de membros da família da artista, costuradas em 1.500 pequenas almofadas que assumem a forma de patuás (amuletos de proteção utilizados por adeptos de religiões de matriz africana), evocando a religiosidade de sua família de origem, caracterizada pela união de catolicismo e umbanda. A forma e o suporte das peças aludem ao ambiente doméstico e à segurança idealmente provida na intimidade, dimensões de outro modo aviltadas em situações de escravização, mas revivificadas pela artista a partir de uma outra posição, a qual lhe permite jogar com a memória, sobrepor camadas temporais e assim extrair-lhe consequências outras, ao modo de uma "terceira imagem" (CARVALHO; TVARDOVSKAS; FUREGATTI, 2018, p. 160), num “deslocamento constante entre a técnica e o mundo social” (COSTA, 2019, p. 8).

Diz a artista: "[...] penso o tempo em forma de camadas. [...] Gosto muito desta ideia de sobreposição, é como se pudéssemos, fisicamente, juntar tempos distintos." (CARVALHO; TVARDOVSKAS; FUREGATTI, 2018, p. 160). A opção pelo paralelismo, em lugar da linearidade e da causalidade direta, permite identificar ou criar fissuras, interrupções, descontinuidades. 
A articulação específica das opressões de raça, gênero e classe presente na obra remete à reabilitação do espaço doméstico como esfera política, uma vez que são os próprios familiares da artista que estão tomando o espaço do museu e incitando reflexões de cunho político e ético. Sem se desvencilhar do componente afetivo, o espaço doméstico surge então como locus do fazer político, a memória sendo usada como matéria-prima para a reflexão e a transformação. O desejo de aniquilação presente em discursos e práticas do período escravocrata é "contrainventado" (no sentido wagneriano) pela artista sob a forma de pessoas representadas de forma individualizada, com repercussões em termos da elaboração da subjetividade no presente, o que pode levar à construção de condições subjetivas e objetivas para um futuro mais promissor.

$\mathrm{Na}$ instalação Aracnes (1996), a artista rende homenagem à aranha, inseto habilidoso com o qual simpatiza, devido ao fato de que, em histórias contadas em várias partes do mundo, ele surge como ser benigno, que participa da criação do mundo (CARVALHO; TVARDOVSKAS; FUREGATTI, 2018). Rosana Paulino conta que enxerga nas capacidades da aranha uma metáfora para o poder criativo feminino, lamentavelmente pouco valorizado em nossa sociedade (CARVALHO; TVARDOVSKAS; FUREGATTI, 2018).

Se em Parede da Memória a intenção é individualizar pessoas negras e recusar o anonimato que historicamente simbolizou a sua desumanização pelos brancos, em Aracnes observamos a força de conexão ou interdependência que reúne histórias densas.

O que se apresenta é uma arquitetura aparentemente sutil, delicada e efêmera, a qual, no entanto, logra resistir a intempéries. Por entre paredes forradas e pontes diáfanas, vislumbramos um desejo de reparação histórica, de restituição do estatuto político de humanidade e de construção de novos referenciais relacionais. De certa forma, essas duas obras pavimentam o caminho de apreensão dos sentidos mobilizados pelos outros três trabalhos abordados a seguir.

Imagem 2: Rosana Paulino. Imagem da instalação Aracnes. Imagens transferidas sobre tecido e fio de poliéster. Dimensão aproximada: 12 m. 1996. 


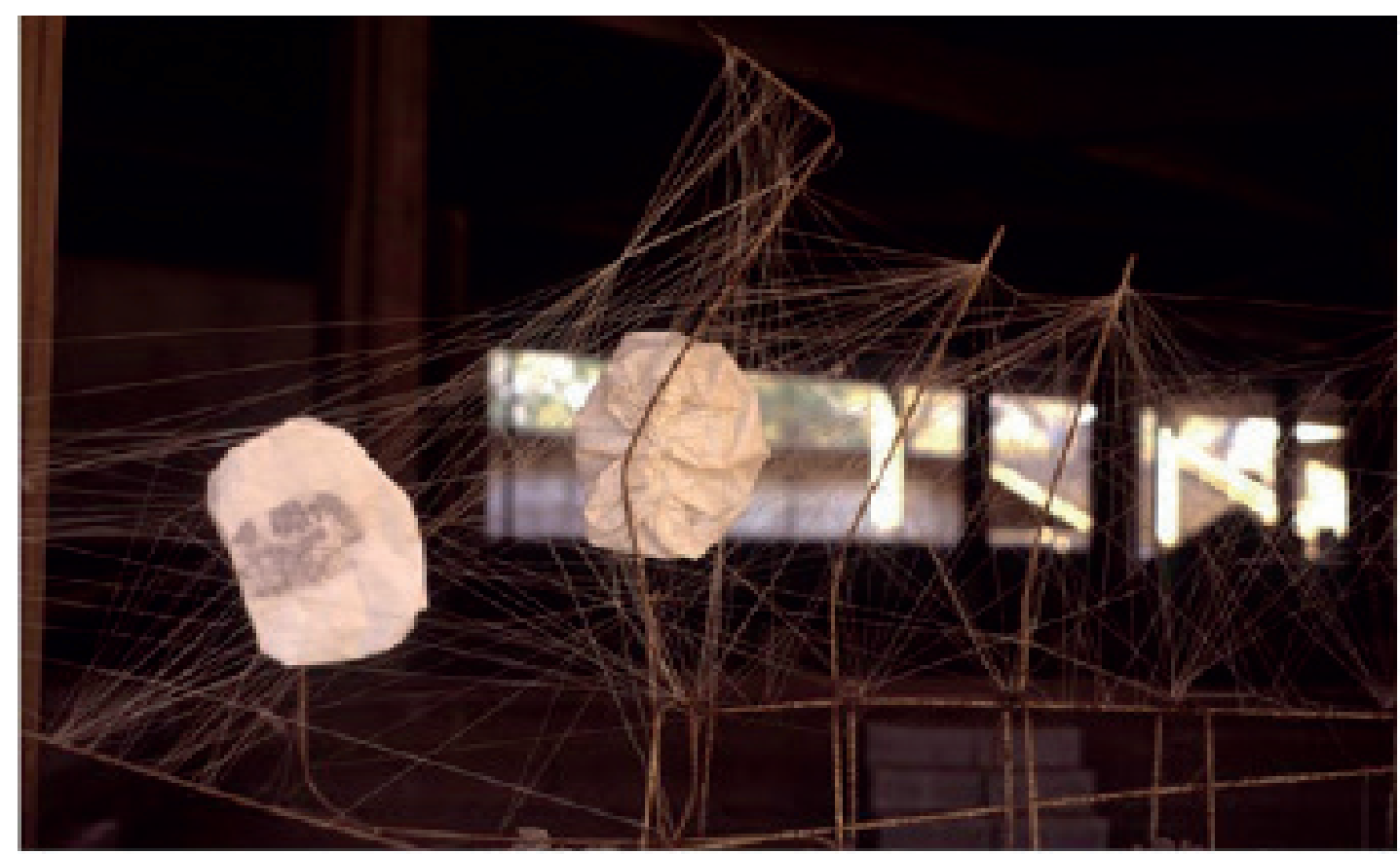

Fonte: Disponível em: http://www.rosanapaulino.com.br/. Acesso em: 14 abr. 2020.

Imagem 3: Rosana Paulino. Imagem parcial da instalação Bastidores. Imagem transferida sobre tecido, bastidor e linha de costura. $30 \mathrm{~cm}$ de diâmetro. 1997.

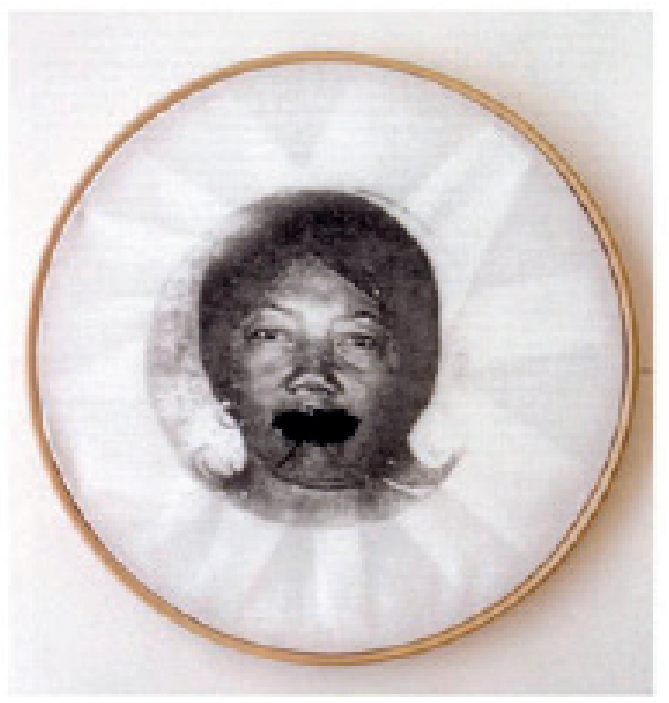

Fonte: Disponível em: http://www.rosanapaulino.com.br/ Acesso em: 14 abr. 2020.

Esta série de 1997 se destaca pelos bordados deliberadamente grosseiros aplicados à 
boca, à garganta, aos olhos e à testa de várias imagens de mulheres. Nessa obra, a artista trabalha o tema da violência doméstica, que acomete mulheres de todos os pertencimentos étnico-raciais, mas principalmente as mulheres negras. A palavra "bastidores" significa tanto suporte para bordado como a parte mais reservada do teatro, aquilo que é ocultado e fisicamente separado do público. Aqui a artista evoca o emudecimento e o cegamento impostos a essas mulheres como meios de privação da participação na vida pública e como subordinação ao masculino. Colocar em contato elementos de um todo que foi desmembrado por meio da costura de pedaços de um passado vivo, rearranjando as partes de modo a lhes conferir consistência e a reativar sua força imanente, mas deixando aparente a realidade aflitiva do corte - esse parece ser o intento maior da artista. O corpo encarnado, violentamente contido ou estranhamente derramado, é um de seus objetos preferenciais. Corpo negro ancestral, denso, que se impõe a uma audiência talvez desejosa de esquecer, minimizar ou relevar os horrores aos quais ele fora relegado.

É preciso ainda sublinhar que, no interior desse universo de criação, a costura não é percebida como coesão harmoniosa, mas sim como aposta num modo de coexistir organizado sobre novas bases. Rosana Paulino consegue politizar a arte ao inventar fios e linhas como metáforas de relações sociais e associações simbólicas duradouras, porém contingenciais, as quais, portanto, podem ser alteradas no curso da história. Ao recusar a caracterização de sua obra como uma espécie de bordado, a artista explica: “[...] não bordo, costuro. E mais que isso: quase sempre uso a costura no sentido de sutura, ou seja, de juntar coisas meio "à força". Isto faz toda a diferença no meu trabalho, já que estou falando de violência" (CARVALHO; TVARDOVSKAS; FUREGATTI, 2018, p. 154).

Imagem 4: Rosana Paulino. Desenho da série Ama de leite. Acrílica e grafite sobre papel - 32,5 x 25,0 cm. 2005. 


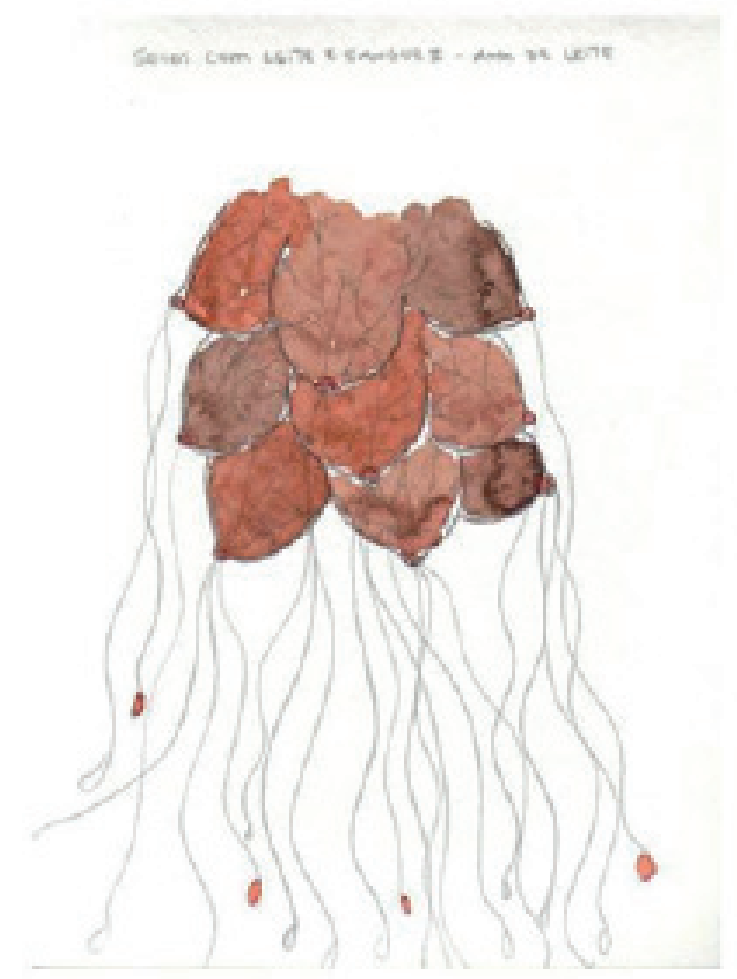

Fonte: Disponível em: http://www.rosanapaulino.com.br/. Acesso em: 14 abr. 2020.

Nesta série de 2005, longos fios jorram de seios negros, uma flagrante alusão ao trabalho de amamentar os filhos dos senhores brancos, trabalho geralmente invisibilizado ou subvalorizado. O título do desenho aqui reproduzido é "Seios com leite e sangue II", evocando diretamente esse tema que, de acordo com Segato (2006), ainda não recebeu a devida atenção da antropologia.

A "mãe preta", que muitas vezes se confundia com a ama de leite ou com a ama-seca, figura central na sociedade brasileira oitocentista, começou a perder espaço ao final do século XIX, à medida que o discurso higienista se consolidava, de modo semelhante ao que ocorreu em outros países latino-americanos. O discurso modernizador de uma nação que gostaria de se ver como branca necessitava erradicar o "inimigo interno", especialmente as mãos negras que mantinham a vida no espaço doméstico, e que passam então a ser vistas como elemento de corrupção física e moral (KOUSTSOUKOS, 2009).

A desvalorização ou apagamento social da mãe preta na sociedade brasileira da virada para o século XX teria levado à emergência de um sujeito que precisa operar uma dupla obli- 
teração, pois se vê arrancado simultaneamente de seu apego ao lugar edípico da Mãe e à mãe individualizada de carne e osso, a mulher negra que alimenta, asseia e nina. Esse vazio psíquico, que encontraria paralelo na ausência de inscrição desse tema na narrativa histórica oficial e na agenda de pesquisa das humanidades, é entendido por Segato (2006) como um movimento de foraclusão dupla, ou seja, uma operação cognitiva e afetiva de desconhecer a um só tempo o materno e o racial, o trabalho de reprodução e a negritude que compõem a sociedade brasileira.

Tal atitude perante o corpo materno teria impactos decisivos para a percepção do corpo feminino e do corpo negro, resultando em sua objetificação, bem como exprimiria o entrelaçamento psíquico de misoginia e racismo. Mas a ausência de recursos de simbolização para reconhecer a mãe e a mulher negra como sujeito, a inviabilidade de as nomear e gramaticalizar enquanto tal, não suplanta, contudo, hábitos e sentimentos sedimentados ao longo de três séculos, e assim, no século XXI, deparamo-nos com incômodas ambivalências nas relações cotidianas, as quais dão margem a enunciados e posicionamentos discriminatórios e excludentes - elementos que parecem constituir a matéria-prima da obra de Rosana Paulino.

Imagem 5. Rosana Paulino. Vista parcial da instalação Assentamento. Vídeo, madeira, paper clay, impressão digital sobre tecido, linóleo e costura. Dimensão variável. 2013.

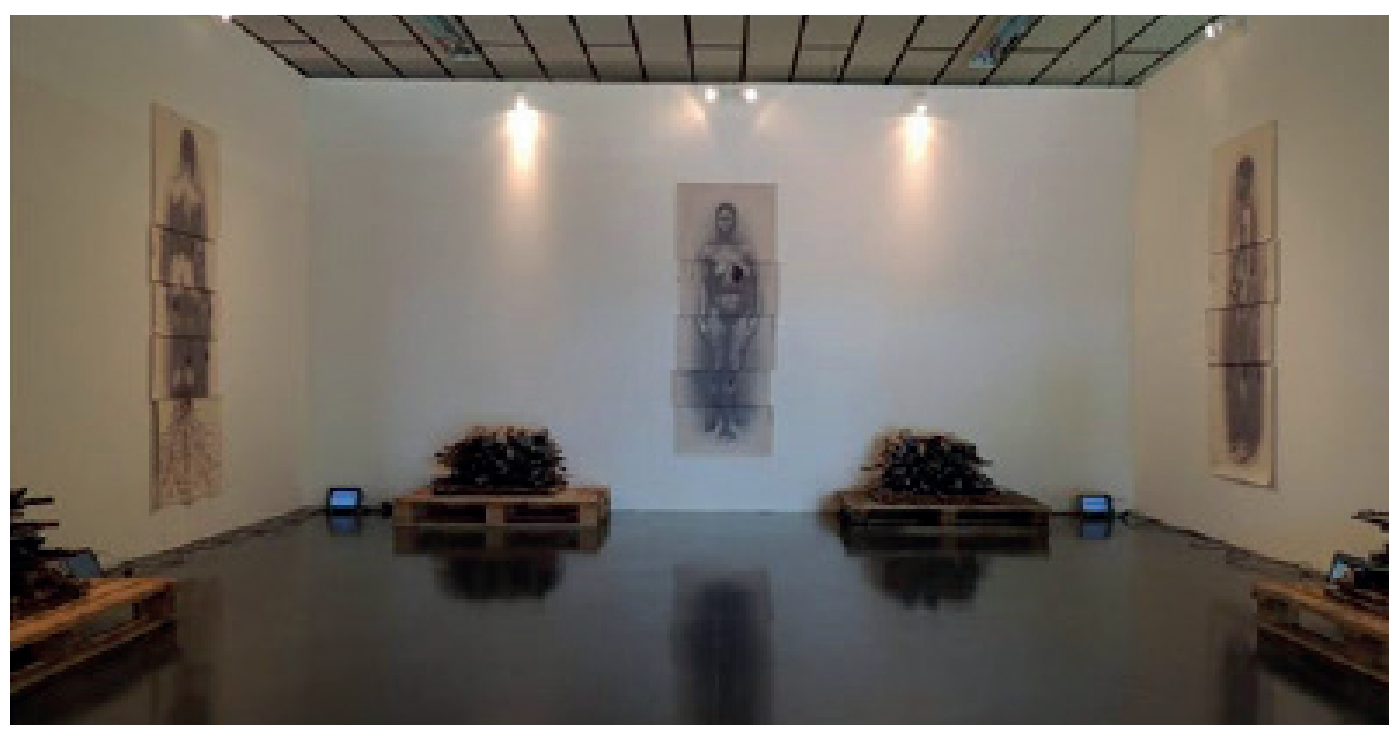

Fonte: Disponível em: http://www.rosanapaulino.com.br/. Acesso em: 14 abr. 2020.

Nessa instalação de 2013, vemos retratos de uma mulher negra feitos por viajantes europeus em meados do século XIX, imagens que comumente ilustram teses alinhadas ao racismo científico, segundo as quais a mistura de raças resultaria em degeneração. A artista amplifica as imagens, recorta-as, costura-as em tecido e monta a figura completa em tamanho real, de modo 
a representar o deslocamento para o primeiro plano da pessoa negra escravizada, que se exibe como elemento fundante da cultura brasileira ${ }^{12}$. Por meio dessa técnica mista, a artista restitui a humanidade e a capacidade de suscitar emoção a um corpo que havia sido desumanizado pelo olhar científico.

Um grande painel de tecido que contém uma dessas imagens reconstituída, na qual sobressai o coração, está posicionado entre duas fogueiras formadas por fardos de madeira e braços negros, o que nos coloca diante da duradoura questão do descarte de pessoas negras. A imagem das pessoas escravizadas como "lenha para queimar", a ideia de que sua força constituía e ainda constitui um objeto de consumo, denuncia, de forma contundente, a desumanidade de quem nega o estatuto de humanidade ao outro racializado.

A instalação conta ainda com vídeos de uma praia, que evocam o som do mar ouvido do interior dos navios negreiros que cruzaram o Atlântico. Com o tempo, porém, o trauma do desenraizamento sociocultural provocado pelo tráfico negreiro, que produziu feridas ainda não cicatrizadas, reverteu-se em um novo enraizamento no território brasileiro, o qual não exclui a ligação com a espiritualidade de matriz africana.

Especificamente sobre a fotografia, a artista pondera o seguinte:

[...] a imagem fotográfica une passado e presente, nos traz informações do que somos hoje, do que nos tornamos. O país de hoje é consequência do passado. Não somos assim por uma decisão divina. As fotos, imagens de ontem, nos dão as pistas para entendermos o que somos hoje. Técnica e conceito se unem para tratar desta passagem do tempo e suas marcas em nossas vidas. (CARVALHO; TVARDOVSKAS; FUREGATTI, 2018, p. 160).

Os retratos oitocentistas de mulheres negras nuas evidenciam a obscenidade do poder colonial. Como escreveu Segato (2012), o olhar colonial é simultaneamente administrador e pornográfico, ou seja, a vulgaridade e a brutalidade eram componentes inseparáveis da gestão da força de trabalho racializada. Práticas de discriminação e opressão articulam-se necessariamente a uma base epistemológica socialmente legitimada, configurando aquilo que Quijano e Mignolo chamam de matriz colonial de poder (MIGNOLO, 2017); no caso do Brasil Império, essa legitimação se consolidou mediante a narrativa cientificista. Conhecedora dos usos sociais dos enunciados científicos, Rosana Paulino assim se posiciona: "A ciência não é neutra. Classifica-se para explorar, para justificar a dominação de um povo por outro. O Brasil ainda está contaminado por essa ideia de racialização de uma pseudociência de 200 anos atrás que justifica

$12 \mathrm{O}$ comentário da artista consta em: https://pinacoteca.org.br/programacao/rosana-paulino/. 
a discriminação racial"' (PASSOS, 2018, n. p.).

Debruçando-se sobre a apropriação do racismo científico para a elaboração de um projeto de nação no final do século XIX, Schwarcz (2003) demonstrou os meandros da associação entre direito e medicina para a definição do modelo de normalidade, que implicava descrever e classificar uma vasta gama de comportamentos "anormais" e assim fixar uma distinção mais fundamental entre humanidade e não humanidade. O Brasil era então retratado internacionalmente como país exuberante, devido à sua composição racial singular, o que o tornava palco de uma espécie de "espetáculo da miscigenação" (SCHWARCZ, 2003, p. 166). Almejando alcançar o "progresso" e a "civilização", e tendo em vista as teorias racialistas em voga na época, a elite intelectual oitocentista elegeu como principal foco de preocupação a questão da "degeneração"; havia então que neutralizar, em termos simbólicos e políticos, as "raças inferiores", etiqueta aplicada aos negros e indígenas, categorias que atrapalhariam o "desenvolvimento" da nação.

No momento de implantação da República, os "homens de sciencia" (médicos e advogados) assumiram a tarefa de elaborar uma justificativa que se pretendia científica para explicar as hierarquias sociais então consolidadas, e para isso recorreram aos modelos darwinistas sociais. Ao focalizar a questão racial sob um viés cientificista, os debates hegemônicos sobre a política nacional se empenhavam em naturalizar privilégios e desigualdades, abusando do tom biológico, determinista, e eliminando a discussão sobre direitos e cidadania: “Transformada em utopia pelos cientistas nacionais, a igualdade conseguida mediante as conquistas políticas era negada em nome da natureza e imediatamente transformada em uma ilusão (Corrêa, 1983)" (SCHWARCZ, 2003, p. 175).

\section{EXAMINANDO 0 TECIDO ESGARÇADO}

Se devemos atentar para a pouca atenção concedida pelas ciências sociais ao tema das “babás”, conforme apontado por Segato (2006), importa lembrar que, nos anos 1980, a supracitada intelectual e ativista negra Lélia Gonzalez se dedicou a refletir sobre a figura da mãe preta. Para Gonzalez (1984), a mãe preta se articularia necessariamente aos estereótipos da mulata e da doméstica, um arranjo que expressaria a "neurose cultural brasileira"13. A autora entendia

$13 \mathrm{O}$ mecanismo básico dessa visão deturpada da realidade social corresponde ao conceito freudiano de denega- 
que esse condicionamento psicológico - uma forma específica de associação entre racismo e sexismo, que tem efeitos nocivos especialmente na vida das mulheres negras - deveria ser desmascarado e enfrentado. Ela explica que a consciência (definida como o discurso do poder dominante) exclui aquilo que a memória inclui, numa relação dialética, porém “[...] a memória tem suas astúcias, seu jogo de cintura: por isso, ela fala através das mancadas do discurso da consciência." (GONZALEZ, 1984, p. 226).

Correal (2019) argumenta que Gonzalez analisou o processo de construção do sujeito dominado em diálogo com as ideias de Frantz Fanon e se perguntava como a dominação se estabelece a partir de processos de alienação e domesticação nos quais o dominado aspira a se parecer com o dominador. Para Gonzalez, a memória restituiria a história não escrita, apresentando-se como lugar de emergência da verdade e espaço de reconhecimento de um passado comum e violento, o que suscita um grito profundo de rebeldia, dignidade e humanidade (CORREAL, 2019, p. 57).

Desse modo, além de alimentar, assear e ninar, importa considerar que a mãe preta ensinava a criança a falar, isto é, a introduzia ao mundo da linguagem e dos sentidos, e por isso desempenhou um papel crucial na formação do sujeito colonial. Gonzalez recupera os dois papéis sociais reservados à mucama no período escravocrata: o de cuidadora (das crianças e dos aposentos da casa-grande) e o de prestadora de serviços sexuais para o homem branco ${ }^{14}$.

Para Gonzalez, tal divisão racial e sexual do trabalho, obliterada no passado, permanecia vigente no século XX, ainda que de forma velada, desdobrando-se nas figuras conectadas em nível simbólico da empregada doméstica (geralmente relegada a condições de trabalho precárias) e da mulata (alvo de desejo dos homens brancos, imagem exaltada no Carnaval). O ocultamento ou a não assunção de uma articulação tão importante corresponderia ao fundamento da culpabilidade branca, que emerge quando o sujeito se vê confrontado com a narrativa hegemônica da democracia racial.

Essa narrativa mítica, que ainda se exprime no rito carnavalesco enquanto espetacularização do componente sexualizado da figura da mulata, impõe um nível agudo de violência simbólica para a mulher negra, o mesmo sujeito que, no cotidiano, é obrigado a usar o elevador

ção, que se refere à atitude de formular um desejo ou pensamento e ao mesmo tempo negá-lo.

14 Em sua leitura da obra de Lélia Gonzalez, Cardoso (2019) explica que no bojo do Sistema Moderno Colonial de Gênero vigorava a premissa de que todas as pessoas colonizadas se transformavam em machos e fêmeas ("nenhuma fêmea colonizada é uma mulher"), premissa que teria orientado as terríveis violências no período escravocrata. O lugar ocupado pelas mulheres negras nesse panorama definiria o padrão de feminilidade associado à mulher branca e o padrão de masculinidade associado ao homem branco, bem como a heterossexualidade como modelo para assegurar a manutenção da configuração familiar branca e cristã. 
de serviço nos prédios de classes média e alta. Impõe igualmente um nível considerável de violência simbólica para o homem negro, nesse movimento destituído da função castradora que, em termos psicanalíticos, compete ao Pai. Outro efeito do mito da democracia racial seria a ideologia do branqueamento, que visa à dominação das pessoas negras mediante a internalização e a reprodução dos valores brancos ocidentais, redundando numa consciência cindida, em que a dependência suplanta a liberdade.

Contudo, Gonzalez (1984, p. 235) afirma que a mãe preta seria a mãe de fato - e essa seria a "rasteira na casa-grande". Do seu ponto de vista, portanto, sustentar tal reinterpretação das relações características do período escravocrata produziria uma consciência emancipada, o que implicaria perceber que, de certa forma, a batalha da cultura brasileira teria sido vencida pelo negro, que emerge então como sujeito capaz de inventar uma linguagem influenciada decisivamente por línguas africanas. Essa linguagem, utilizada também pelos brancos, é chamada de "pretuguês" e se revelaria como uma expressão de força e criatividade em um contexto de assujeitamento e exploração. Bem, parece-me plausível pensar essa reinterpretação como uma espécie de "contrainvenção" (no sentido wagneriano) da narrativa-mestra da nação - de modo análogo ao que realiza Rosana Paulino em suas obras de arte.

A noção de "pretuguês" coloca a necessidade de reconhecer a existência de uma linguagem popular singular que se insinua no interior da casa-grande, a fim de formular uma linguagem acadêmica alternativa capaz de refundar essa narrativa-mestra em bases anticolonialistas e antipatriarcalistas. Desse modo, conceitos como "amefricanidade" e "Améfrica Ladina", utilizados por Gonzalez, sintetizam uma epistemologia plural que não apaga o conflito e a violência e que mantém aberta a possibilidade de transformação do atual estado de coisas. Tais conceitos, que remetem a uma forma poético-política afro-brasileira, articuladora de modalidades de resistência conscientes e inconscientes, permitem inserir o pensamento da autora numa ampla tradição pan-africana, que faz uso da noção de dupla consciência formulada pelo sociólogo e ativista negro W. E. Du Bois para se referir a identidades diaspóricas, que transcendem os Estados-nação e as fronteiras étnicas e constituem espaços translocais nos quais se formam movimentos políticos, estéticos e intelectuais (GÓES; LÁO-MONTES, 2019, p. 52).

Gonzalez defendia o protagonismo das pessoas negras na interpretação de sua própria história e situação social, daí a ênfase em uma concepção pedagógica que vem sendo tomada como um feminismo negro descolonial pioneiro, ligado ao engendramento de políticas de libertação e sensibilidades críticas que oferecem ferramentas de luta e recursos de esperança (GÓES; LÁO-MONTES, 2019, p. 54).

Entretecendo os fios burilados por Lélia Gonzalez, intelectuais brasileiras e de outros 
países latino-americanos têm elaborado propostas político-epistemológicas pulsantes, como, por exemplo, o faz Correal (2019), ao defender que não se pode desconhecer a realidade pluricultural e multirracial da América Latina, mas que, para afirmá-la adequadamente, é necessário conceitualizar as identidades como móveis e diaspóricas, abertas a possibilidades de agregação, como um meio e não como um fim, ou seja, reconhecer que se trata de distintas posicionalidades que constroem uma subjetividade subalterna múltipla face à colonialidade do poder. Para ela, o presente requer uma esperança realista que desloque o ódio e o medo, duas emoções que a experiência colonial colocou no centro da relação entre sujeitos diferentes e desiguais e que ainda hoje nos acompanham (CORREAL, 2019, p. 58).

\section{FINALIZANDO A COSTURA}

Rosana Paulino recorre à alegoria do Frankenstein para sintetizar sua visão sobre o país: “O Brasil é um país Frankenstein. Se você pega partes diferentes e tenta juntar na marra, é claro que essa história não vai dar certo" (PASSOS, 2018, on-line). A operação de desmascaramento dessa alegoria implica uma "contrainvenção" (no sentido wagneriano) das relações de opressão baseadas no critério racial, mediante a articulação de uma linguagem visual desafiadora, exposta em um lugar tradicionalmente reservado à exibição da arte erudita (produzida pela e para a elite branca), colocando-se em relevo continuidades históricas perturbadoras.

Nesse sentido, a cisão evidenciada pela técnica da sutura parece pertencer ao plano do devir, ao modo de uma antecipação da descontinuidade relacional que se quer ver projetada no âmbito coletivo, nacional, e que é a um só tempo presentificada pela própria obra e personificada por sua autora. O resultado é uma espécie de fusão espaciotemporal, que assume a forma de um novo modelo relacional que não se fundamente na opressão ou na denegação. Como talvez dissesse Lélia Gonzalez, nessas obras, a astúcia da memória se impõe contra o desejo interessado de esquecimento.

A esta altura, espero ter conseguido demonstrar que Rosana Paulino alinhava com rara habilidade os domínios do autobiográfico e do histórico, do tradicional/artesanal e da crítica política contemporânea, da arte e da ciência, revelando assim um desejo de interrupção de formas de opressão racializadas. Na narrativa autorreflexiva da artista, as distinções entre bordado e costura (enquanto sinônimo de sutura) e entre estética e técnica se desdobram em uma distinção de ordem conceitual e política, levando-nos a perceber que o todo não equivale exatamente 
à soma das partes. $\mathrm{O}$ jogo com as percepções de dentro e fora, direito e avesso, delicado e grosseiro (mal-acabado) produz uma sensação de ambiguidade e deslocamento que pode gerar algum nível de incerteza, algum espaço para o estranhamento em relação àquilo a que estamos habituados ou para a aproximação em relação ao desconhecido, e quiçá também um impulso em direção à adoção de uma outra perspectiva visual, que neste caso corresponderia a uma postura ética. O manejo habilidoso do "sentido político-poético das imagens" trabalhadas por Rosana Paulino (CARVALHO; TVARDOVSKAS; FUREGATTI, 2018) consiste, portanto, em uma contribuição de valor inestimável para a formulação de uma estética e uma subjetividade contra-hegemônicas.

Ao sugerir que a política se faz também dentro da galeria de arte, pretendo reafirmar a qualidade fundamentalmente etnográfica da noção de política e endossar a proposta de pensadoras e ativistas feministas para as quais o ponto de intersecção das diferentes opressões é um lugar de luta, criação e transformação ${ }^{15}$. Ademais, ao provocar o encontro entre as obras de arte de Rosana Paulino e as reflexões epistemológicas de Lélia Gonzalez, a antropologia mostra que pode contribuir com a imaginação de novas possibilidades de conceber e viver o domínio do político.

Assim, ao evocarem a potência da mãe preta, cada uma a seu modo e em seu tempo, Rosana Paulino e Lélia Gonzalez chamam a nossa atenção para uma matriz feminina de forças de engendramento e sustentação de condições de vida, forças que costumam ser negligenciadas ou minimizadas nas análises políticas predominantes. Essa espécie de tecnologia imaginativa manejada por ambas investe no valor das práticas micropolíticas de resistência e inovação, as quais se apoiam nos laços de interdependência, configurando um contraponto relevante às práticas macropolíticas que focalizam tecnologias de produção de assujeitamento, desumanização e morte. Em síntese, essas duas mulheres provenientes das margens nos mostram, com sua obra e sua atuação, que o alargamento simbólico da linguagem pode modificar nossa relação com o mundo.

Mergulhar na experimentação artística realizada por Rosana Paulino pode nos levar a olhar para nós mesmas(os) e nos reconhecer como parte desse "país-Frankenstein", o que possivelmente implicará assumir que sua feiura se alastra para todas as partes de seu corpo e não será suprimida com novos remendos pontuais, mas talvez nos leve também a reconhecer e valorizar elementos comumente varridos para debaixo do tapete do eurocentrismo. Por outro lado, compreendermo-nos como "amefricanos", como propôs Lélia Gonzalez, implica embarcarmos

15 Ver, por exemplo, DAVIS, 2016. 
em uma experimentação epistemológica descolonial que contempla a valorização das diversas experiências políticas, culturais, estéticas e religiosas de resistência no contexto da diáspora, bem como se contrapõe a interpretações centradas na visão de mundo europeia. Essas duas modalidades de experimentação, que se contrapõem incisivamente à experimentação necropolítica analisada por Mbembe, constituem-se, enfim, como poéticas que escancaram feridas antigas e apontam tratamentos que não venham a apagar as cicatrizes históricas.

Nesses tempos em que o culto ao ódio e ao medo predomina na vida política, parece imprescindível atentar para formas singelas de expansão de horizontes e de superação de opressões. Se este é também o tempo de nos "aquilombar", como convocou Conceição Evaristo, lembrando-nos de que "a liberdade é uma luta constante" ${ }^{16}$, cabe sublinhar que novas miradas podem motivar novos afetos, emoções, ideias e posicionamentos, influenciando decisivamente a configuração de novas subjetividades e novas disposições políticas. Por isso penso, juntamente com Roy Wagner, que a antropologia, ao se aproximar das artes em termos simétricos, pode inventar outras perspectivas e relações conscientes da diferença e da contradição, ao mesmo tempo que adia o seu próprio "fim" 17 e, simultaneamente, pode contribuir para a multiplicação das formas de estar no mundo. Que os fios da criatividade logrem sempre se movimentar contra as políticas de morte, desafiando os sentidos e significados por elas agenciados.

\section{REFERÊNCIAS}

1. ALVES, Jaime Amparo. Topografias da violência: necropoder e governamentalidade espacial em São Paulo. Revista do Departamento de Geografia da USP, v. 22, p. 108$134,2011$.

2. BIENAL Naïfs do Brasil-SESC/Rosana Paulino, 2016. (5 min 24 s). Disponível em: https://www.youtube.com/watch?v=nCke_NCI2Xw\&list=PLtukD4KW-eVIfnysACk9 91QA7mK70zsYX\&index=55\&t=0s. Acesso em: 11 jan. 2020.

3. BRAH, Avtar. Diferença, diversidade e diferenciação. Cadernos Pagu, Campinas, n. 26, p. 329-376, 2006.

16 “Tempo de nos aquilombar”. Conceição Evaristo. O Globo, 31 dez. 2019. Disponível em: https://oglobo.globo. com/cultura/em-textos-ineditos-escritores-expressam-desejos-para-2020-1-24165702 Acesso em: 1 jan. 2020.

17 Estou me referindo à provocação feita por Goldman (2011) a propósito das implicações mais gerais da obra de R. Wagner para a disciplina. 
4. BRAVO! Ateliê da artista/Rosana Paulino, 2018. (5 min 7 s). Disponível em: https:// www.youtube.com/watch?v=1TdnSyqWv1A. Acesso em: 11 jan. 2020.

5. CARDOSO, Cláudia Pons. Amefricanidade: proposta feminista negra de organização política e transformação social. DOSSIER El pensamiento de Lélia Gonzalez, un legado y un horizonte. Fórum. Latin American Studies Association, v. 50, n. 3, p. 44-49, 2019.

6. CARVALHO, Noel dos Santos; TVARDOVSKAS, Luana Saturnino; FUREGATTI, Sylvia Helena. A propósito da passagem de Rosana Paulino pela Unicamp: entrevista com a artista. Resgate: Revista Interdisciplinar de Cultura, Campinas, v. 26, n. 2 [36], p. 149-160, 2018.

7. CAVALCANTE, Jordhanna Neris Sampaio. Sobrevivendo no inferno da 'democracia' no Brasil pós-1988. 2019. 83 f. Monografia (Graduação em Sociologia) - Departamento de Sociologia, Universidade de Brasília, Brasília, 2019.

8. COLLINS, Patricia Hill. Pensamento feminista negro: o poder da autodefinição. In: HOLlANDA, H. B. de. (org.) Pensamento feminista: conceitos fundamentais. Rio de Janeiro: Bazar do Tempo, 2019. p. 271-310.

9. CORREAL, Diana Gomes. Améfrica Ladina, Abya Yala y Nuestra América: tejiendo esperanzas realistas. DOSSIER El pensamiento de Lélia Gonzalez, un legado y un horizonte. Fórum. Latin American Studies Association, v. 50, n. 3, p. 55-59, 2019.

10. COSTA, Marcela Rossiter Lima. Rosana Paulino: tensões entre passado, presente e futuro. 2019. Relatório de pesquisa da iniciação científica - Departamento de Sociologia, Universidade de Brasília, Brasília, 2019.

11. DAVIS, Angela. Mulheres, raça e classe. São Paulo: Boitempo, 2016.

12. DIÁLOGOS Ausentes/Itaú Cultural/Rosana Paulino, 2016 (9 min 24s). Disponível em: https://www.youtube.com/watch?v=7awdUzh9UVg. Acesso em: 10 dez. 2019.

13. DOSSIER El pensamiento de Lélia Gonzalez, un legado y un horizonte. Fórum. Latin American Studies Association, 50: 3, p. 41-79, 2019. Disponível em: https://forum.lasaweb.org/past-issues/vol50-issue3.php?fbclid=IwAR0yh7CR I9wPzzVYcKp3poo1wSK2in6km11xAfKCKiNpKhyAMTKvRPOSfY. Acesso em: 10 dez. 2019.

14. ENTREOLHARES/Itaú Cultural/Rosana Paulino, 2017 (22 min 56 s). Disponível em: https://www.itaucultural.org.br/entreolhares-2017. Acesso em: 24 jan. 2020.

15. FERREIRA, Débora Armelin. As tramas de Rosana Paulino. 2020. Disponível em: http://www.afreaka.com.br/notas/tramas-de-rosana-paulino/. Acesso em: 03 jan. 2020.

16. FOUCAULT, Michel. Microfísica do Poder. Rio de Janeiro: Edições Graal, 2018.

17. GÓES, Juliana; LÁO-MONTES, Agustin. Nossa Améfrica en clave dos feminismos 
pretos: el imaginario geohistótico de Lélia Gonzalez. DOSSIER El pensamiento de Lélia Gonzalez, un legado y un horizonte. Fórum. Latin American Studies Association, v. 50, n. 3, p. 50-54, 2019.

18. GOLDMAN, Marcio. O fim da antropologia. Novos Estudos Cebrap, São Paulo, n. 89, p. 195-211, 2011.

19. GONZALEZ, Lélia. Racismo e Sexismo na Cultura Brasileira. Revista Ciências Sociais Hoje, p. 223-244, 1984.

20. GONZALEZ, Lélia. A categoria político-cultural da Amefricanidade. In: HOLLANDA, H. B. de. (org.) Pensamento feminista: conceitos fundamentais. Rio de Janeiro: Bazar do Tempo, 2019. p. 341-352.

21. JESUS, Carolina Maria de. Quarto de despejo: diário de uma favelada. 10. ed. São Paulo: Ática, 2014.

22. KOUTSOUKOS, Sandra Sofia Machado. "Amas mercenárias": o discurso dos doutores em medicina e os retratos de amas - Brasil, segunda metade do século XIX. História, Ciência, Saúde - Manguinhos, Rio de Janeiro, v.16, n.2, p. 305-324, 2009.

23. KUSCHNIR, Karina. Antropologia e política. Revista Brasileira de Ciências Sociais, v.22, n. 64, p. 163-167, 2007.

24. LIMA, Fátima. Bio-necropolítica: diálogos entre Michel Foucault e Achille Mbembe. Arquivos Brasileiros de Psicologia, Rio de Janeiro, v. 70, p. 20-33, 2018.

25. MARQUES, Tatiana Lee; MYCZKOWSKI, Rafael Schultz. Identidade tecida: Rosana Paulino costurando os sentidos da mulher negra. Revista Estúdio, Lisboa, v. 7, n. 13, p. 95-103, 2016.

26. MENEZES, Hélio. Rosana Paulino: a sutura da história. C\&América Latina, 27 fev. 2019. Disponível em: http://amlatina.contemporaryand.com/pt/editorial/rosanapaulino-the-suturing-of-history/. Acesso em: 15 jan. 2020.

27. MBEMBE, Achille. Necropolítica. Temáticas. Arte \& Ensaios, n. 32, p. 123-151, 2016.

28. MIGNOLO, Walter. Colonialidade. O lado mais escuro da modernidade. Revista Brasileira de Ciências Sociais, São Paulo, v. 32, n. 94, p. 1-18, 2017 e329402. Disponível em:https://www.scielo.br/scielo.php?pid=S0102-69092017000200507\&script=sci_ abstract\&tlng=pt. Acesso em: 12 jan. 2020)

29. O CORPO negro nas obras de Rosana Paulino, 2017. (3 min 47 s). Disponível em: https://www.youtube.com/watch?v=Y8NMJLyKiXw. Acesso em: 09 dez. 2019.

30. NOVAIS, Karyna Barbosa. A mulher negra na obra de Rosana Paulino: oficina de artes visuais e cultura afro-brasileira. In: SEMINÁRIO INTERNACIONAL DE PESQUISA EM ARTE E CULTURA VISUAL, 2., 2018, Goiânia. Anais... Goiânia: UFG, 2018. p. 764-774. Disponível em: https://seminarioculturavisual.fav.ufg.br/up/778/o/LC_ 
KARYNA_NOVAIS_IISIPACV2018.pdf. Acesso em: 10 dez. 2019.

31. PASSOS, Úrsula. Rosana Paulino costura ciência, mulheres e negros em mostra na Pinacoteca. Folha de São Paulo, 2018. Disponível em: https://www1.folha.uol.com. br/ilustrada/2018/12/rosana-paulino-costura-ciencia-mulheres-e-negros-em-mostra-napinacoteca.shtml. Acesso em: 03 jan. 2020.

32. PEIRANO, Mariza. Antropologia política, ciência política e antropologia da política. In: PEIRANO, Mariza. Três ensaios breves. Brasília: UnB, 1997. p. 17-29. (n. 230).

33. PINHO, Osmundo. Lutas culturais: relações raciais, antropologia e política no Brasil. Sociedade e Cultura, Goiânia, v. 10, n. 1, p. 81-94, 2007.

34. PINHO, Osmundo. Introduction. DOSSIER El pensamiento de Lélia Gonzalez, un legado y un horizonte. Fórum. Latin American Studies Association, v. 50, n. 3, p. 41-43, 2019.

35. REINA, Andrei. Sutura da arte no tecido social. Revista Bravo!, 07 set. 2018. Disponível em: https://medium.com/revista-bravo/rosana-paulino-e-a-sutura-da-arte-no-tecidosocial-brasileiro-9bdb7f744b4e. Acesso em: 15 jan. 2020.

36. SCHWARCZ, Lilia Moritz. O espetáculo da miscigenação. In: DOMINGUES, H. M. B.; SÁ, M. R.; GLICK, T. (org.) A recepção do darwinismo no Brasil. Rio de Janeiro: Editora Fiocruz, 2003. p. 164-180.

37. SEGATO, Rita. O Édipo brasileiro: a dupla negação de gênero e raça. Brasília: UnB, 2006. 21 p. (Série Antropologia; n. 400).

38. SEGATO, R. Gênero e colonialidade: em busca de chaves de leitura e de um vocabulário estratégico descolonial. e-cadernos CES [online], v.18, p. 106-131, 2012. Disponível em: https://journals.openedition.org/eces/1533. Acesso em: 15 jan. 2020

39. SIMIONI, Ana Paula. Bordado e transgressão: questões de gênero na arte de Rosana Paulino e Rosana Palazyan. Proa - Revista de Antropologia e Arte, ano 02, v.1, n. 2, 2010. Disponível em: http://www.ifch.unicamp.br/proa/ArtigosII/anasimioni.html. Acesso em: 15 jan. 2020.

40. VERBETE Rosana Paulino na Enciclopédia Itaú Cultural. 2020. Disponível em: http:// enciclopedia.itaucultural.org.br/pessoa216153/rosana-paulino. Acesso em: 10 jan. 2020.

41. WAGNER, Roy. A invenção da cultura. São Paulo: Cosac \& Naify, 2012.

Giovana Acacia Tempesta

Doutora em Antropologia Social pela Universidade de Brasília e atualmente é pesquisadoracolaboradora vinculada ao Programa de Pós-Graduação em Antropologia Social da mesma universidade. ID ORCID: http://orcid.org/0000-0002-0469-1473. E-mail: giovana.tempesta@ gmail.com. 